\title{
Adaptation of buildings to climate change through bioclimatic strategies, in Romania.
}

\author{
Anca Bodale ${ }^{1,2^{*}}$, Tiberiu Catalina ${ }^{1,2}$, and Sima Cătălin Ionuț $t^{1,2}$ \\ ${ }^{1}$ Technical University of Civil Engineering, Faculty of Building Services Bucharest, Romania \\ 2 OVER 4 Solar Decathlon Association - Romanian Representative for SD2019
}

\begin{abstract}
.
Climate change has become a fundamental concern for scientific researchers, architects and engineers, and requires improving the performance of the sectors responsible for city and building infrastructure. Burning fossil fuels to produce electricity and heat are the biggest cause of climate change and emissions and represent one third of total greenhouse gas emissions. Thus, buildings become responsible for improving the external environment, either by construction phases, rehabilitating process or by maintaining process. In Romania the building sector is the main contributor to gas emission and most of the residential multi-storeys constructions are buildings from the communist period built using standardized projects. In Romania one the main goals are the thermal rehabilitation of buildings and construction of apartments especially in the inner circle of the capital. However, the renovation measures are very basic and do not target actual/future EU legislation that imposes the Nearly Zero Energy Building (NZEB) standard for the buildings. To overcome and to provide an alternative to both correct refurbishment and creation of new apartments the OVER 4 prototype was developed. These prototypes are modules of apartments where multiple bioclimatic strategies were implemented to minimize the energy consumption. Using the Passive House Project Planning (PHPP) the module was 3D created and simulated to reach the optimal architecture for both well-being of residents and the energy balance.
\end{abstract}

\section{CONTEXT}

According to the bioclimatic principles, we can consider the local climate as one of the fundamental factors in the study of the bioclimatic strategies, which influence the design of the constructions. A first bioclimatic principle is the reduction of mechanized systems that require electricity consumption. About $60 \%$ of the total energy produced in our planet is consumed by the footprint reflected by city and building infrastructure, and so, energy becomes a major source for cooling/ ventilation, heating, lighting, maintenance and all the building construction. [1]

The primary method of controlling the indoor climate of buildings was due to "passive architecture", is based on passive and bioclimatic principles and strategies. Returning to the current global environment, the evolution of technology has become a necessary tool in building systems, thus reducing primary passive solutions as much as possible.

According to several scholarly researches' climate change falls into two hypotheses: The first is due to human activities and the second explains the process of climate warming as a natural phenomenon. In both cases, the production and combustion of certain combustion amplifiers the greenhouse effect.

By doing so, we focus on the effect of electricity and heating production, which accounts for $30.6 \%$ of total causes due to anthropological action. Thus, according to the World Resources Institute (WRI), combustion of fossil fuels to produce electricity and heat is the biggest cause of climate change and emissions make up one third of total greenhouse gas emissions. [2]

Until now, construction in Romania required approximately $300-350 \mathrm{kWh} / \mathrm{m}^{2} /$ year but with the new renovation measures reached $90-150 \mathrm{kWh} / \mathrm{m}^{2} /$ year according to the Romanian standards [3]. There is an enormous energy consumption that can be reduced to 15 $\mathrm{kWh} / \mathrm{m}^{2} /$ year where passive building principles are applied. [4]

\subsection{Climate change in Romania}

Following the research carried out by the National Meteorological Administration [5], the future changes in the climate regime in Romania are in the global context considering the regional conditions, and thus the most pronounced temperature will be in the summer, while in the northwest of Europe, the temperature will be in the winter. For Romania, with the simulations made by the global climate model HadAM3H [6] for the comparison and forecasting of temperature differences between 1960 -1990 and 2070 - 2090, a major difference in temperature increase was observed, such as:

- increase of temperature between $0.5^{\circ} \mathrm{C}$ and $1.5^{\circ} \mathrm{C}$ for the period $2020-2029$;

- increase of temperature between $2.0^{\circ} \mathrm{C}$ and $5.0^{\circ} \mathrm{C}$ for $2090-2099$ depending on the scenario (e.g. between $2.0^{\circ} \mathrm{C}$ and $2.5^{\circ} \mathrm{C}$ for the scenario with the lowest average temperature increase and between $4.0^{\circ} \mathrm{C}$ and $5.0^{\circ} \mathrm{C}$ for the most prominent temperature rise scenario).

National climate change will influence ecosystems, human settlements and infrastructure. Major changes in temperature and precipitation may result in extreme weather events such as heat waves, wind storms, seeding, floods and the like, which will consequently lead to significant damage to the construction infrastructure.

\subsection{Bioclimatic Principles for Local Climate in Romania}

By analyzing the global climatic zones, warm climate zones and cold climates, it can be observed the methods for energy efficient building through passive strategies, focusing on the following directions: for the warm 
climate, passive techniques for sun protection, passive ventilation techniques and cooling, while for the cold climate, passive strategies focus on passive techniques for natural lighting and heating. [7]

In the Continental climate, also found in Romania, the concerns are concentrated on all passive systems correlated with a temperate continental transition climate specific to central Europe with four distinct seasons: spring, summer, autumn and winter. Thus, for Romania, the need for bioclimatic design prioritizes the following categories:

- passive ventilation and cooling techniques during the warm season;

- passive heating techniques during the cold season;

- passive winter lighting techniques;

- passive sunscreen techniques during summer.

\subsection{Adaptation of buildings to climate change}

In the context of climate change, one of the most important directions is represented by the need of dumping the building sector, thus making the regeneration of the space built as a priority objective. A series of questions are necessarily among one of the most important: What is the adaptation to climate change?

According to the scientific definition, adapting to climate change is the ability of all natural and anthropogenic systems to react to the current, expected climate change and climate variability with the primary purpose of reducing damage. This adaptation can be studied in several ways: Anticipatory and reactive, private and public, autonomous and programmed. [8]

Regarding building infrastructure, adaptation to climate conditions is a complex process because changes vary from one region to another depending on climatic zones (attention paid to climate zones in Romania).

Adaptation requires action at all levels, local, regional, national and international, looking from the perspective of all sectors (economy, social, transport, construction, etc.).

At European level, we find the policies launched in 2007-2009 that support the following statement on adaptation to the effects of climate change, the sooner it will be addressed, "the lower the costs of limiting the negative effects of climate change." In 2013, the strategy is backed by General Recommendations presented to all EU countries. Constructions in Romania will have to cope with the impact of much higher summer temperatures, much lower winter temperatures, more intense winds, more rain and more abundant snow. Up to now, the Eurocodes and national norms are based on specialized weather maps and the like, which are not fully up to date with the need to adapt buildings to future climate change. These should be reviewed periodically to ensure they keep up with the changing knowledge and conditions. [9]

\subsection{Retrofitting solutions of communist block of flats}

Retrofitting an existing building can oftentimes be more cost-effective than building a new one. Because the existing buildings represent the largest segment of the built environment, and the process of demolishing a large block of old buildings is not a sustainable solution, it is important to initiate energy conservation retrofits solutions to eliminate the impact of a demolition and to reduce energy consumption and the cost of heating, cooling, and lighting buildings.

But conserving energy is not the only reason for retrofitting existing buildings. The goal is to create a high-performance building by applying new improvements starting from structure, envelope, materials and installations. By doing a retrofitting process to the existing buildings, they will be less costly to operate, they will increase in architectural/structural quality, last longer, and contribute to a healthier and more qualitative environment for people in which to live and work.

\section{The Over4 prototype}

\section{1 The renovation proposal}

Buildings are responsible for most of Romanian's energy consumption. The residential and tertiary sector (offices, commercial spaces and other non-residential buildings) account for $46 \%$ of total national energy consumption [10]. Two decisive periods stand out in the morphological analysis of the dwelling areas in the city of Bucharest:

1. The 1965-1975 period marks the appearance of the collective dwelling organized in micro-terrains, carried out by industrialized means and, in most cases, according to some standardized projects. Large peripheral living quarters (dormitory quarters) were constructed on previously unoccupied land (for example, Balta Albă Titan, Drumul Taberei, Berceni, Pajura) or by taking over the existing urban fabric (for example, Militari quarters).

2. The 1975-1990 period concerns the construction of large peripheral assemblies. Existing assemblies are restructured (complete rebuilding of the frontal streets and landscapes for the Lacul Tei, Moşilor, Ştefan cel Mare, Mihai Bravu areas). The period also includes the radical restructuring of some peripheral areas previously occupied by individual dwellings (Colentina, Pantelimon, Pipera, Băneasa, Crângaşi, etc).

The present study focuses on the analysis of large residential complexes (1964-1990): Balta Alba, Titan, Sud-Berceni, Drumul Taberei, Giuleşti, Crangasi, Militari, Lacul Tei, Doamna Ghica, Rahova, Parcul Tineretului, Nitu Vasile, etc.

In Romania we have a significant legacy of prefabricated blocks that are inefficient from the energy point of view as well as ensuring interior comfort conditions. Thus, we identify for Romania the following statistics:

- $72 \%$ of residential buildings in Romania are collective dwellings;

- $87 \%$ of collective dwellings were built before 1990

- $60 \%$ of collective dwellings have 4 floors;

- $80 \%$ of these current collective buildings will be inhabited in 2050;

- Only $1 \%$ of these buildings have been renovated. Over4 prototype propose a holistic approach to the whole rehabilitation process of the existing fund, and we focus 
on reducing energy consumption and environmental impact to achieve the NZEB standard.

Following these statistics, in Romania, collective housing in the communist period occupies a large percentage (about 70\%) of the urban housing stock. Many of these have not yet been rehabilitated, either at local standards or at European standards. Five-tier prefabricated blocks, namely the 770-83 series, were built massively in response to a high demand for housing, without regard to comfort conditions. Over time, this type of housing has become even more problematic, requiring immediate intervention.

The main goal of the Over4 project is to improve the way in which the collective dwelling blocks built during the communist period are currently being renovated in Romania. Over4 aims to develop and implement an Integrated Rehabilitation pilot project applicable to the $\mathrm{G}$ +4 floors blocks (type 770-83) built during the communist period, which fulfills the objectives and requirements of the European Union regarding the reduction of the energy consumption and the environmental impact for residential buildings. (according to Directive 844/2018). The 770-83 G+4 floors block of flats is the most widespread in Romania (over 4,500 blocks identified in Bucharest in just 9 neighborhoods), and similar models are spread across Eastern Europe. [10]

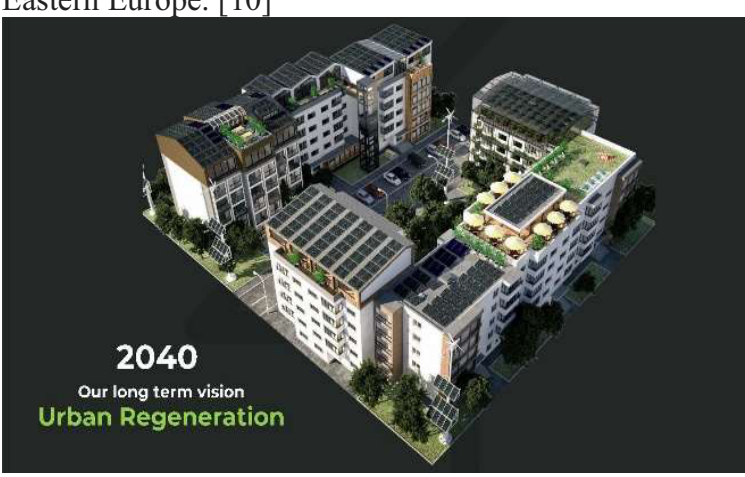

Fig. 1. Graphic realized by Over4. Urban Regeneration 2040

\subsection{The architecture concept of the module}

The OVER4 prototype consists of one rooftop extension module proposed on the existing 770 block of flats type, where it was calculated that it can fit up to 6 identical modules.

Considering that all the modules on the block share common walls on all the sides except for one of the facades, a thick thermal insulation layer will cover the eastern, western and northern walls, to mimic a minimal loss of thermal energy. The only wall with windows will be on the south facade, doubled by zenithal illumination responsible with facilitating the cross ventilation and the evacuation of the hot air during the summer. The angle of the slope is calculated by the angle of incidence of the solar rays.
An additional strip of semitransparent photovoltaics will be placed on top of the south terrace to allow the light to go further inside the house and for the shading system to cover it during summer. [10]

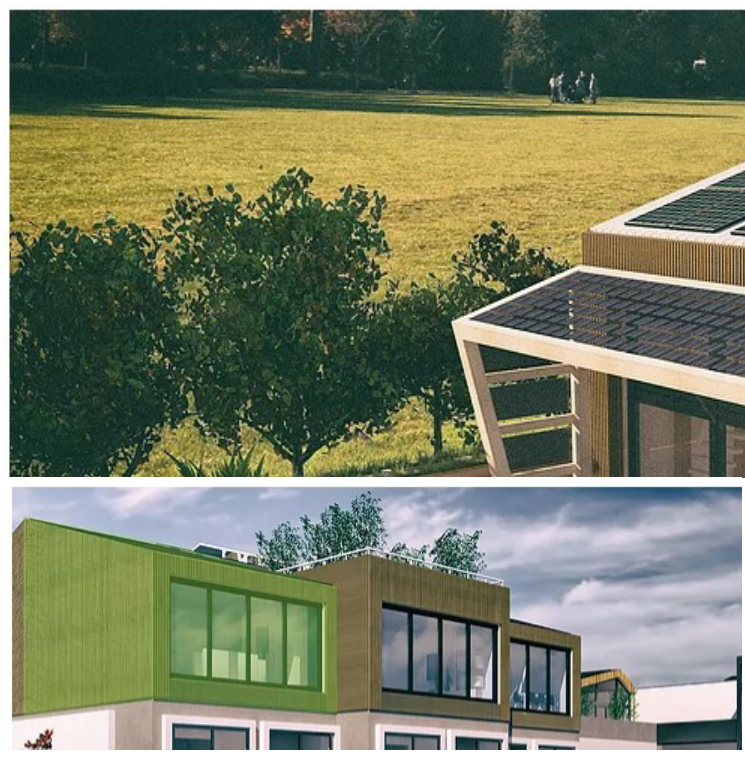

Fig. 2. The OVER 4 modular Prototype and integration on 770 roofs

The Over4 architectural design is made entirely of wood panels, including the exterior and interior finishing will be made out wood or wood derivatives. Thus, a unique and pleasant atmosphere will be created while paying close attention to the material's sustainability and their impact on the environment. While designing the prototype the over4 kept in mind three key principles: modularity, passive design and most importantly, the user's experience.

The Over 4 project has built area of 144.72 sqm with a heated/cooled surface of $62.13 \mathrm{sqm}$. The other surfaces of the prototype are summarized in Table 1:

Table 1. Building areas

\begin{tabular}{|l|r|}
\hline Ground floor \\
\hline Toilet & $3.01 \mathrm{sqm}$ \\
\hline Kitchen & $2.37 \mathrm{sqm}$ \\
\hline Living and dinning & $33.57 \mathrm{sqm}$ \\
\hline Technical room & $5.1 \mathrm{sqm}$ \\
\hline $\mathbf{1}^{\text {st }}$ floor & \\
\hline Access hall & $3.39 \mathrm{sqm}$ \\
\hline Balcony & $8.07 \mathrm{sqm}$ \\
\hline Bathroom & $2.68 \mathrm{sqm}$ \\
\hline Bedroom & $9.88 \mathrm{sqm}$ \\
\hline Lounge space & $5.05 \mathrm{sqm}$ \\
\hline
\end{tabular}


The prototype is a functional home, is thought to adapt to the current generation and its needs. For this reason, the internal scenario is based on the transformability and flexibility of space and its furniture. The home is designed for a couple of two people with the possibility to reconfigure the space to adapt the guest house.

\subsection{Bioclimatic strategies}

The bioclimatic strategies of the Over4 project are to improve the energy efficiency of the building and to reduce energy consumption to the final consumer through the creation of buffer spaces through bioclimatic architecture as well as through the following passive solutions like:

- Effective thermal insulation: requires a high performance thermal insulation of the opaque elements of the tire to achieve values of the thermal transfer coefficient $\left(\mathrm{U}_{\text {envelope }} \leq 0.15\right.$ $\mathrm{W} / \mathrm{m}^{2} \mathrm{~K}$ ) in order to achieve higher resistance of the building at extreme temperatures and humidity;

- Energy-efficient windows: glazed elements and frames must be energy-efficient for which the transmission coefficient must be lower than $\mathrm{U}_{\text {window }} \leq 0.8 \mathrm{~W} / \mathrm{m}^{2} \mathrm{~K}$ and the solar radiation transmission $(\mathrm{g})$ of at least $50 \%$;

- Eliminating thermal bridges or reducing them to very low thermal conductivity $\lambda \leq 0.01 \mathrm{~W} / \mathrm{mK}$ is also a very important objective aiming substantial reduction of heat losses;

- The air tightness of the envelope: envelope elements must be extremely well-established, with infiltration rates of $\leq 1.0[\mathrm{vol} / \mathrm{h}]$ for an inward/outward pressure difference of $50 \mathrm{~Pa}$, to eliminate the infiltration of low- and hightemperature summer air drafts that can interfere with the indoor microclimate, and which generates additional costs to restore it as well as reducing the risk of building degradation.

Other strategies were implemented in the prototype: compact form, orientation, the use of shading systems, passive preheating or passage of fresh air, the use of renewable energy sources, intelligent automation system and finally the use of energy-efficient home appliances.

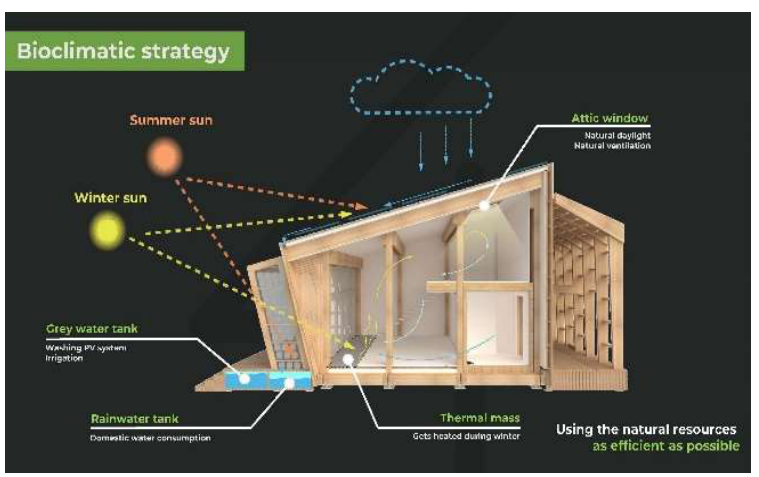

Fig.3. Bioclimatic strategies for the OVER 4 prototype

\subsection{Structural concept}

The structural system must be able to withstand its own weight, plus the weight of the installations equipment mounted inside the panel and the dynamic loading such as the seismic or wind actions. Thus, wood was chosen as structural material, more precisely Cross Laminated Timber, also known as CLT, because it is renewable, and its structural properties could be compared to that of steel when we consider resistance to density. Furthermore, wood is the most sustainable structural material because of its low weight which means that foundations could be smaller because the overall loading of the foundation is smaller and that means lower costs and, in addition to that, the carbon footprint of wood is much smaller than that of steel or concrete. To make one cubic meter of wood, 6 kilograms of $\mathrm{CO}_{2}$ are released into the atmosphere, whereas for steel there are 76 kilograms of $\mathrm{CO}_{2}$ released and for concrete even more, with 101 kilograms of $\mathrm{CO}_{2}$ released. Because wood is a light material, the overall seismic design force will be smaller and thus smaller sections can be used for the structural elements and further material economy can be made. By using glued wood, we eliminate all fire regarded problems, because the glue can be treated to repel fire and it could also combat natural pests that damage wood. In order to make the prefabricated modules that are placed around the apartment blocks, CLT panels are chosen, because they can be easily prefabricated and delivered on site with thermal insulation, HVAC and plumbing installations and the exterior finish, all embedded in the module. By using these prefabricated panels, the modularity issue is solved, and no further structural problems are induced because the exterior modules are able to withstand on their own the dead weight loading and the lateral seismic loading. Using this system, depending on the characteristics of the whole structure, the structural engineer can decide if the exterior panels must interact or not with the concrete structure to obtain a better seismic response. Because the choice was to construct with prefabricated panels, it is safe to sustain that the modularity design concept is achieved. Moreover, this aspect is addressing all the architectural, energy efficiency and structural issues that have been damaging these buildings over the past decades, without making the occupants leave their homes for better and safer ones.[10]

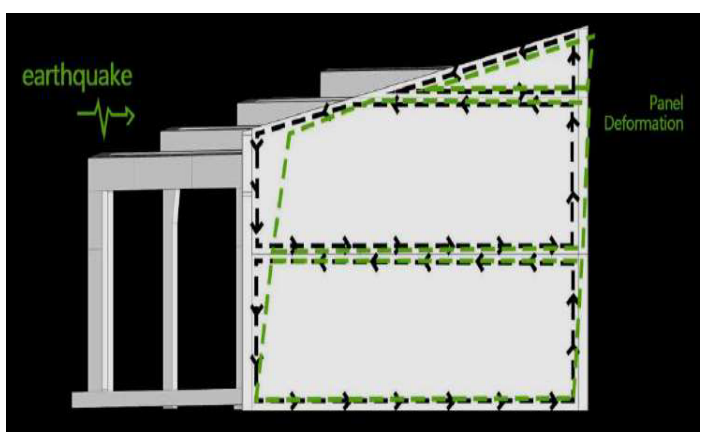

Fig.4. Structural concept of earthquake movement

The structure also comprises photovoltaic panels that are to be placed on the roof, mounted on a structure 
and tilted with a southern orientation. During winter, the panels will be inclined at a steep angle, for a better performance and for avoiding damage by snow accumulation. The mounting structure will have an adjustable tilt for maintenance and performance reasons.

\section{Energy consumption simulations}

Passive buildings or energy-efficient projects designed using computing program have proven to be successful, whether they are being for new or rehabilitated constructions. These projects are meant to meet the "EnerPHit" or "PassiveHouse" standards with respect of comfort and low energy consumption. In addition, in most cases the projects are cost-effectively. In addition to applying the "PassiveHouse" concept and passive technologies, the use of the Passive House Project Planning (PHPP) as a planning tool remains one of the most important bases for the implementation of sustainable building concepts. Using the selected climatic data as the basic boundary conditions (especially temperature and solar radiation) for the location where the assessed building is located, the PHPP software calculates the heating or cooling demand. The calculations are computed immediately with the change of an input parameter; therefore we can have access on the effect on the building's energy balance. For the OVER4 prototype it was possible to compare architectural design and other components and thus optimize the specific construction project. The calculated values are compared to the limit values imposed within the specific certification criteria for the type of building studied by validating or invalidating whether the building under consideration meets or does not meet the PHI certification criteria. Several advantages were found using this simulation program among which the development of the 3D model which will later was exported to Passive House Project Planning (PHPP) module. The iterative design created by the designPH program is meant for calculating an energy balance directly from the 3D model. Therefore, the design can be modified in real-time and a rapid visualization of the workflow and energy consumptions is possible. We also found interesting this program at it can be used as a learning tool for teachers and students to better understand the passive house concepts and to access accurate and rapid results. To prepare and make a house at the passive standard or to do such analysis, designPH should be used with PHPP. DesignPH uses advanced calculation method for heating or assessment of summer comfort.

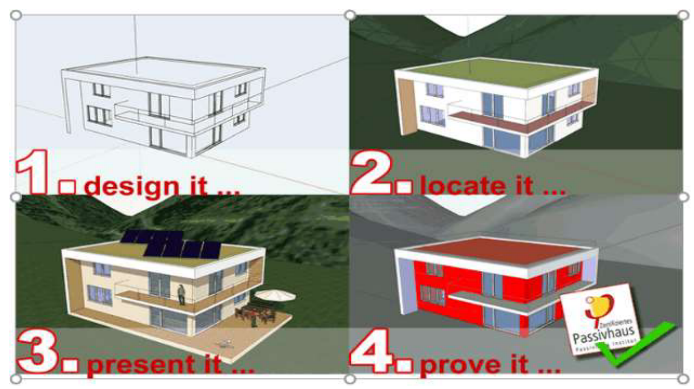

Fig.5. Flow diagram of PHPP certification
The workflow in designPH for the OVER 4 prototype follows these steps:

- Development of the project in the 3D interface (see Figure 6);

- Selection of the orientation in the 3D model and climate data;

- Performing the analysis to get a preliminary energy balance value, edit the properties and optimize the design;

- Verify that the project is optimized for the passive standard by exporting to PHPP module.

-

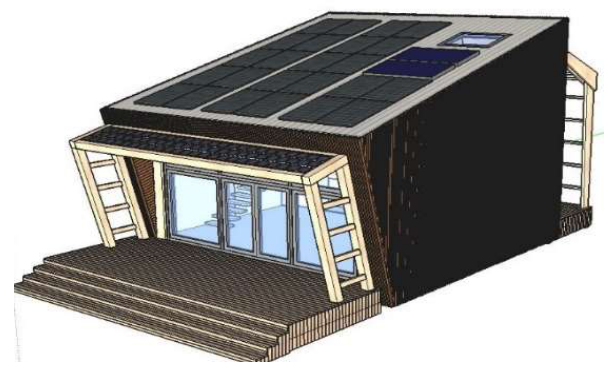

Fig. 6. 3D model of the OVER 4 project analyzed in designPH

To summarize the steps of the analysis Figure 5 is a perfect way to illustrate this aspect. The workflow from PHPP module is also divided in several secondary stages:

- Importing the 3D model;

- Assigning a climatic region to calculate the thermal balance in the "Climat" tab;

- Assignment of thermal characteristics (U-value, capacity, density, etc.) for opaque surfaces;

- Assignment of thermal characteristics (U-value, type, transmittance, etc.) for the fenestration;

- Adding the shading elements, creating surfaces that have a shading effect on window components;

- Assigning thermal bridges to different parts of the envelope;

- Other details related to indoor gains, HVAC scenarios and finally the calculation to benchmark the proposed module.

One of the principles underpinning the passive house is to have an energy-efficient glazed surface and to find a balance between the heat loss through these surfaces and the sun solar radiation. Thus, it can be seen from the two charts that we have a glazed surface loss of only 15.5 $\mathrm{kWh} / \mathrm{m}^{2} /$ year and a heat input from the sun of $55.2 \mathrm{kWh}$ $/ \mathrm{m}^{2} /$ year, resulting in a huge solar gain of about 3.5 times higher than the heat losses. The presented data are valid for Bucharest weather conditions. 


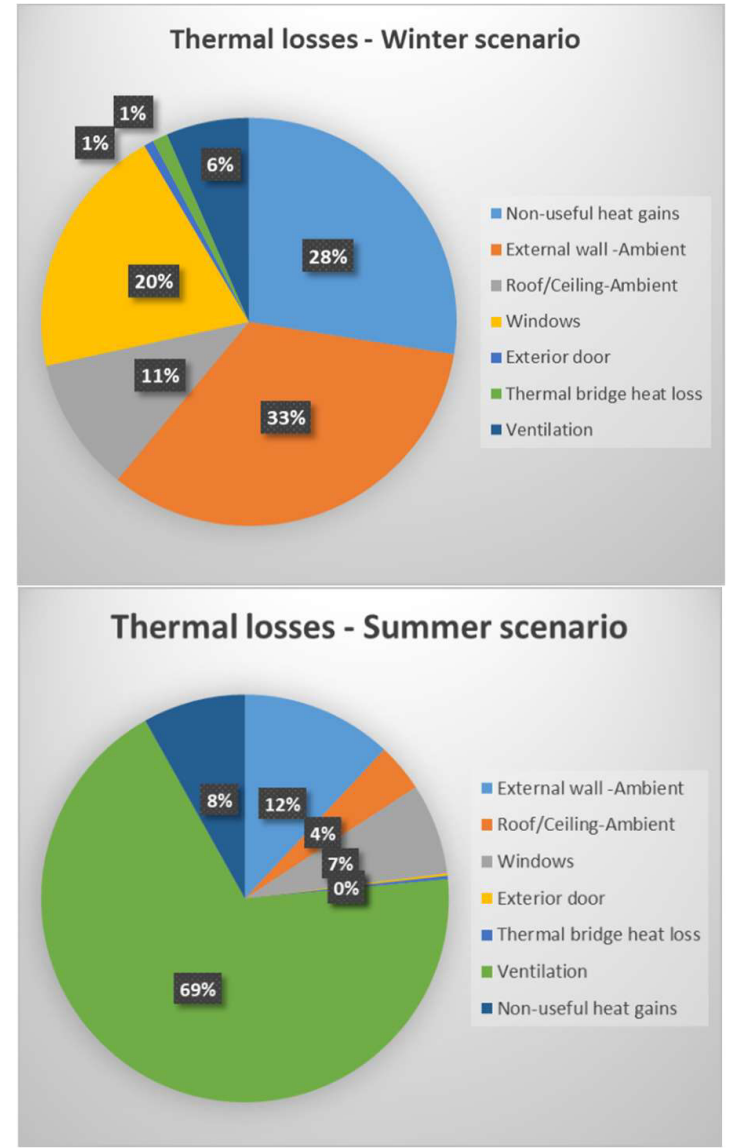

Table 2. Winter and summer energy demand

\begin{tabular}{|l|r|}
\hline \multicolumn{2}{|l|}{ Winter heat gains (kWh/m $/$ year) } \\
\hline Solar heat gains & 55.2 \\
\hline Internal heat gains & 14.2 \\
\hline Heating demand & 6.9 \\
\hline Summer heat gains (kWh/m²/year) \\
\hline Non-useful heat losses & 49.5 \\
\hline Solar heat load & 29 \\
\hline Internal heat load & 31.2 \\
\hline Cooling demand & 7.9 \\
\hline
\end{tabular}

Non-useful heat losses represent the difference between total heat losses and useful heat losses.

The glazed surface has been chosen to help reduce winter consumption, but an important consideration to be taken into consideration during the summer period is to have shading measures to avoid overheating.

After the simulations the overheating coefficient obtained is only $8 \%$, lower than what is required by the passive house criteria. Even so, we found that this value is too high and to solve this problem, we opted for an air-to-air heat pump air-conditioning system and the use of the night cooling principle, which led to "removing" the heat from the indoor environment by recirculated the cooler air during the night after as it can be seen in the first graph, helped to meet the consumption requirement of less than
$15 \mathrm{kWh} / \mathrm{m}^{2}$ year for heating and cooling imposed by the passive house standards.

\section{Conclusions}

This paper presented the role of buildings in the context of climate change, especially for the Romanian climate. Moreover, buildings should be designed to respond to climate change and to adapt using bioclimatic strategies for: energy conservation, reduction of electricity consumption for cooling and ventilation systems and, last but not least, for reduction of emissions of $\mathrm{CO}_{2}$. The process of demolishing buildings consumes resources and energy and its not a sustainable solution. It is important to initiate energy conservation retrofits solutions to eliminate the impact of a demolition and to reduce energy consumption and the cost of heating, cooling, and lighting buildings. In this context, the Over 4 is a pilot project for the rehabilitation of communist-era blocks, a process of retrofitting, and more so, it brings added value to the energy performance of buildings. The benefits of the Over 4 rehabilitation pilot project include: 1. Structural Rehabilitation 2. Increased life duration 3. Energy efficiency 4. Functional rehabilitation 5. Increased the quality of the Interior. Also, for the prototype the benefits include some qualities like, modularity of the structure, transformability of the interior space and quality of the interior conditions which respond to air, sound, energy, humidity, natural light and ventilation. Over 4 is a solution to improve the building infrastructure in terms of energy performance in Romania.

\section{References}

[1] J. Burck, U. Hagen, F. Marten, N. Höhne, C. Bals, CCPI-climate change performance index, Germanwatch and New climate institute \& Climate Action Network, (2019).

[2] R. P. Lejano, Climate change and the relational city, Cities, Volume 85, pp 25-29, (2019)

[3] Romanian Methodology of energy performance of buildings MC001/1-2006

[4]C. Becchio, S.P. Corgnati, V. Monetti, E. Fabrizio, From high performing buildings to nearly zero energy buildings: potential of an existing office building, Climamed Conference, Proceedings book (2013).

[5]Romanian Meteorological Agency http://www.meteoromania.ro/anm/images/clima/SSCGhi dASC.pdf

[6] Hudson, DA \& Jones, RG. Simulations of Present-Day and Future Climate over Southern Africa using HadAM3H. Hadley Centre Technical Note, (2002).

[7]National Strategy on Climate Change and Growth based on Low Carbon Emissions for 2016-2020, Annex $1,2016$.

[8]Government of Romania, Ministry of Environment and climatic change, http://www.mmediu.ro/ (2019)

[9] Passive House Institute (PHI) Literature and Tools, https://passivehouse.com $/ 05$ service $/ 05$ _literature_en.ht m (2019)

[10] OVER 4 Solar Decathlon Association - Romanian Representative for SD2019, Over4 documentation, https://www.over4.org/ (2019). 